\title{
Wind Energy: A Review Paper
}

\author{
${ }^{1}$ Atul Kumar \\ M S College, \\ ${ }^{1}$ Motihari, India \\ 1atulmth1@gmail.com
}

\author{
${ }^{2}$ Muhammad Zafar Ullah Khan \\ University of Management \& \\ Technology, Sialkot Campus, Pakistan \\ 2acd.dir@skt.umt.edu.pk
}

\author{
${ }^{3}$ Bishwajeet Pandey \\ Gyancity Research Lab, \\ Motihari, India \\ gyancity@gyancity.com
}

Abstract- This review paper examined the outline of wind innovation, where the approach depends on standards and down to earth executions. Wind vitality is the second biggest wellspring of sustainable power source after hydropower. It is incredibly reasonable, yet it is discontinuous. Even though the abuse of twist goes back a few centuries, the cutting edge wind vitality industry started amid the oil emergency of the seventies. Most these days wind turbines are onshore; however others are fabricated seaward, more often than not in wind ranches. Since wind vitality is discontinuous, it must be upheld by different wellsprings of power. Wind vitality can be productive as a rule. However, it has not yet accomplished full matrix equality with fossil vitality sources.

Keywords- Literature Survey; Wind Forecasting Categories; Wind Speed and Power Forecasting Methods.

\section{Wind Energy- Introduction:}

Rising oil costs feature the abuse of sustainable power source applications. Wind vitality is a standout amongst the most appealing sustainable power source advancements on account of its high proficiency and low contamination [1]. Be that as it may, since the vitality created by wind vitality transformation frameworks (WECS) changes with environmental meteorology and wind speed [2-3], surprising varieties in WECS vitality generation may expand the working expenses of the electrical structure in light of the fact that the stores will be developed and the potential dangers will be put for the unwavering quality of the power supply [4]. Power lattice administrators need to anticipate changes in wind control age to program turning save limit and oversee arrange tasks [4]. To lessen hold limit and increment wind infiltration, precise gauging of wind speed is required [5]. What's more, the forecast of wind vitality assumes a vital part in the portion of balance control. What's more, the breeze vitality conjecture is utilised for the day by day programming of conventional power plants and the commercialisation of power in the spot advertise [6]. Even though the conjecture precision of the breeze vitality figure is lower than the expectation exactness of the heap gauge. Wind vitality gauges still assume a crucial part in tackling the issues of misusing power supply. As of late, a few techniques have been utilised for the forecast of wind vitality. Various written works have been dedicated to enhancing wind vitality anticipating approaches by analysts with broad involvement in field preliminaries. A few techniques for estimating wind vitality have been created and propelled on wind ranches.

We can characterise into six gatherings to anticipate wind vitality: tirelessness strategy, physical technique, factual strategy, spatial relationship strategy, human-made reasoning strategy and cross breed approach. [7-15] As indicated by the latest World Wind Energy Association (WWEA) information, even in 2009, the time of the worldwide money related emergency, the world's aggregate introduced limit will achieve 152,000 MW before the finish of 2009 [3] This implies in 2009, there will be 30,300 MW of newly introduced limit, which compares to a development of $25 \%$ contrasted with the earlier year (Fig.1).

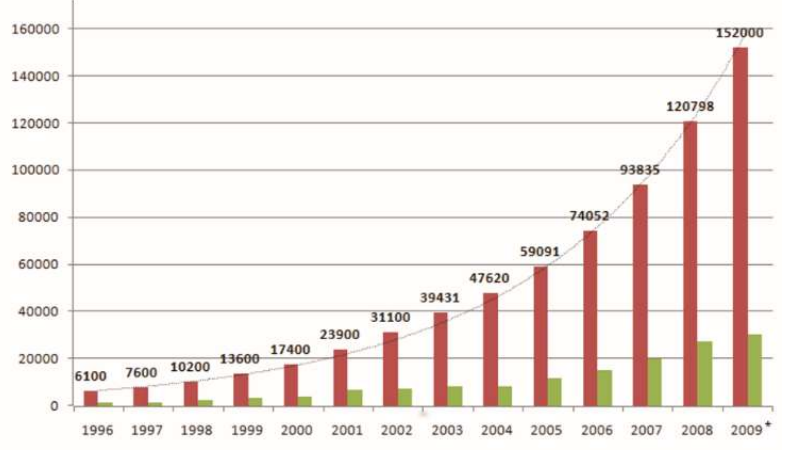

Fig. 1. Worldwide growing (red) and worldwide yearly (green) mounted wind capacity. (2009 predicted value).

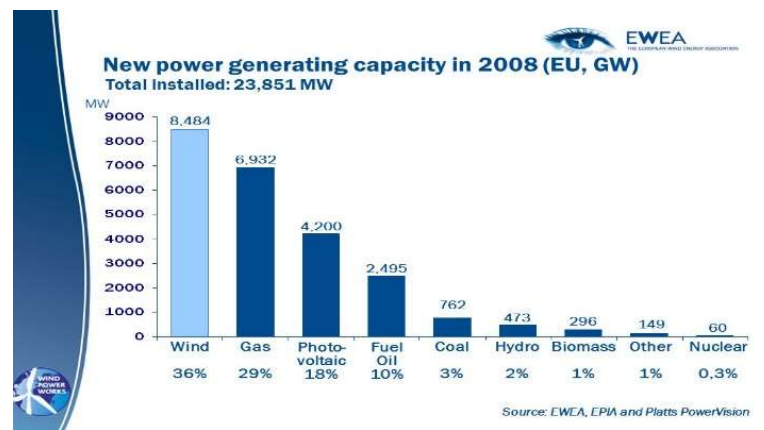

Fig. 2.Recently mounted power capacity in EU, 2008 
As per the report of The European Wind Energy Association (EWEA), the year 2008 in the EU was the chief year in which more breeze control was introduced than some other power creating innovation, (Fig.2).

\section{Wind Energy:}

Wind vitality is a changed over type of sunlight based vitality that is created by the atomic combination of hydrogen $(\mathrm{H})$ into helium $(\mathrm{He})$ in its core. The $\mathrm{H} \rightarrow \mathrm{He}$ dissolving process makes streams of warmth and electromagnetic radiation from the sun to space every which way. Albeit the Earth catches just a little division of sunpowered radiation, it gives the more significant part of the Earth's vitality needs. Wind vitality is a noteworthy wellspring of cutting-edge dynamism, and a notable player in the worldwide vibrancy advertise. As a best in class vitality innovation, the specialised development and quick organisation of wind vitality are perceived, just like the absence of a down to earth furthest point of confinement for the level of wind that can be coordinated into the electrical framework [1]. It has been assessed that the aggregate sun oriented vitality got by the Earth is around $1.8 \times$ $1011 \mathrm{MW}$. Of this sun based info, just $2 \%(3.6 \times 109 \mathrm{MW})$ is changed over to wind vitality, and around $35 \%$ of wind vitality scatters inside $1,000 \mathrm{~m}$ of the Earth's surface [2]. Subsequently, accessible breeze vitality that can be changed over into different types of energy is roughly $1.26 \times 109 \mathrm{MW}$. Since this esteem speaks to 20 times the present rate of worldwide vitality utilisation, wind vitality could on a fundamental level fulfil the everyday vitality needs of the world. Contrasted with familiar vitality sources, wind vitality has numerous favourable circumstances and advantages. Not at all like petroleum derivatives that radiate explosive gases and atomic dynamism that creates radioactive waste, wind vitality is a clean and naturally amicable wellspring of energy. As an endless and free wellspring of life, it is accessible and plentiful in many parts of the world. Furthermore, more widespread utilisation of wind vitality would help diminish the interest for non-renewable energy sources, which could be exhausted sooner or later in this century, contingent upon their present usage. Moreover, the cost per kWh of wind vitality is much lower than that of sun oriented energy [3]. In this way, as the most encouraging vitality source, it is trusted that breeze vitality assumes an essential part in global vitality supply in the 21 st century.

\section{Wind Energy Equation:}

\section{a) Wind speed-}

$$
P=\frac{1}{2} \rho A V^{3}
$$

The measure of vitality in the breeze shifts with the solid shape of the breeze speed, at the end of the day, if the breeze speed copies, there is eight times more vitality in the breeze $\left(2^{3}=2 x 2 x 2=8\right)$. Little varieties in wind speed mostly affect the measure of energy accessible in the breeze.

b) The density of the air-

The denser the sky, the more vitality the turbine gets. The thickness of air shifts with height and temperature. The atmosphere is less thick at high altitude than adrift level, and warm air is less compressed than chilly air. Every single other thing being equivalent, turbines will deliver more power at bringing down heights and in places where average temperatures are colder.

\section{c) The swept area of the turbine-}

The bigger the region cleared (the measure of the rotational part of the rotor), the more noteworthy the power that the turbine can get from the breeze. Since the cleared territory is, the place span of the rotor, a little increment in edge length brings about a more significant increase in the accessible power for the turbine.

\section{Wind Turbines:}

Wind turbines fabricate power to abuse the moderate intensity of the breeze to drive a generator. The breeze could be a clean and property supply of fuel, it doesn't create discharges and it'll ne'er run out since it's interminably restored with the vitality of the sun. In some ways, wind turbines zone unit the character advancement of old windmills, anyway presently they here and there have three cutting edges, that spin around a flat shape at the most elevated of a steel tower. One in all the chief usual and vogue turbine styles could be a metal pinnacle with a three-sharp edge rotor appeared in Figure 3. 


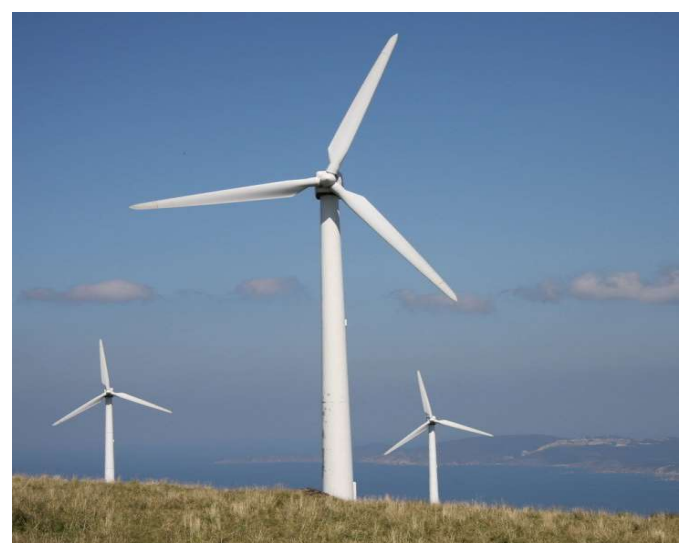

Fig.3. NEG Micon 1.5MW Wind Turbine, 68m diameter Rotor, Tubular Steel Tower. Blades are made up of fibreglass. The Rotor blades can be Turned to optimise power \& the entire tower is rotated to face the wind.

Most breeze turbines begin creating power at twist speeds in the request of 3-4 meters for each second $(\mathrm{m} / \mathrm{s})(8$ miles for every hour); produce an "ostensible" greatest power at around $15 \mathrm{~m} / \mathrm{s}(30 \mathrm{mph})$; and close to stop the harm of the tempest at twenty-five $\mathrm{m} / \mathrm{s}$ or more $(50 \mathrm{mph})$.

a) Almost all the power on Earth is made with any rotating engine,

b) Turbine: change of the rectilinear stream development to the turn of the pole through pivoting streamlined surfaces

Underneath Table 1 demonstrates the unique kinds of age and it is rotating the motor and Figure 4 indicates diverse sorts of turbines.[18]

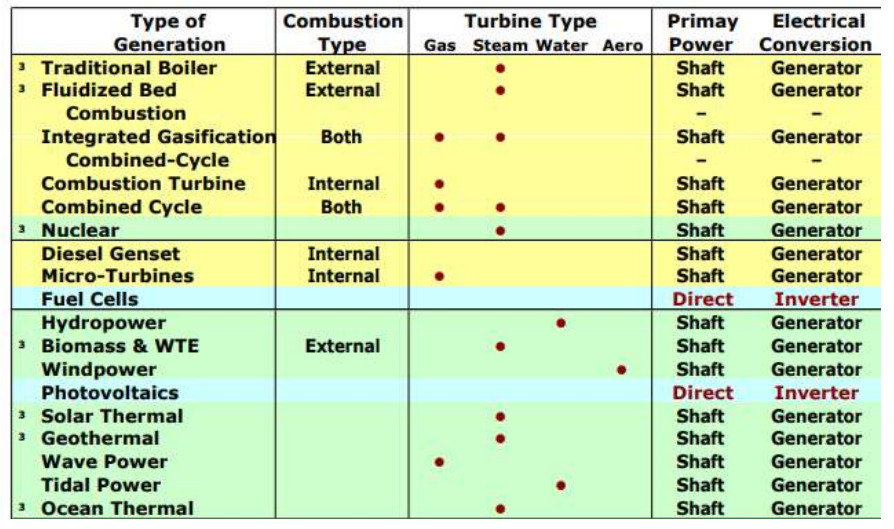

Table 1. Different types of generation and its Turbine type

\section{Wind Turbine Technology:}

Regardless of whether wind ranches can fit the new matrix codes relies upon the innovation of the breeze turbines. There territory unit 3 basic styles of revolving engine|turbine $\}$ s utilised these days: the mounted speed twist turbine with confine Induction Generator, the variable speed turbine with Doubly Fed Induction Generator and in this manner the variable speed turbine with Synchronous Generator. The mounted speed confines Induction Generator expends receptive power and can't add to voltage administration. Hence, however static capacitance administration may allow twist ranches with this sort of generators to deliver responsive power, this sort of generators territory unit bound to vanish from wind turbines. The variable speed turbine with Doubly Fed Induction Generator are regularly management led to deliver recurrence and voltage control with a succeeding converter inside the rotor. Control code redesign and equipment adjustments region unit essential, a considerable measure of precision, the convertorratings may be expanded for recurrence reaction [39]. This kind of generator shows a few troubles in going through voltage bounces, since the consequences of the voltage drop create high voltages and streams in the rotor circuit and, therefore, the power converter can break. This can be the principal broadened variable speed turbine innovation and creators as of now furnish this sort of twist turbines with blame ride-through abilities. The variable speed turbine with Synchronous Generator is associated through a succeeding converter to the lattice. This gives most adaptability, facultative full genuine and receptive power administration and blames ride-through capacity all through voltage plunges. Once more, control code update and minor equipment change zone unit essential to add to the framework soundness. Different elements like site particular load coordinating (when the yearly breeze profile correlates the heap) and a high scope of twist turbines inside the power station encourage wash the task of the network. 


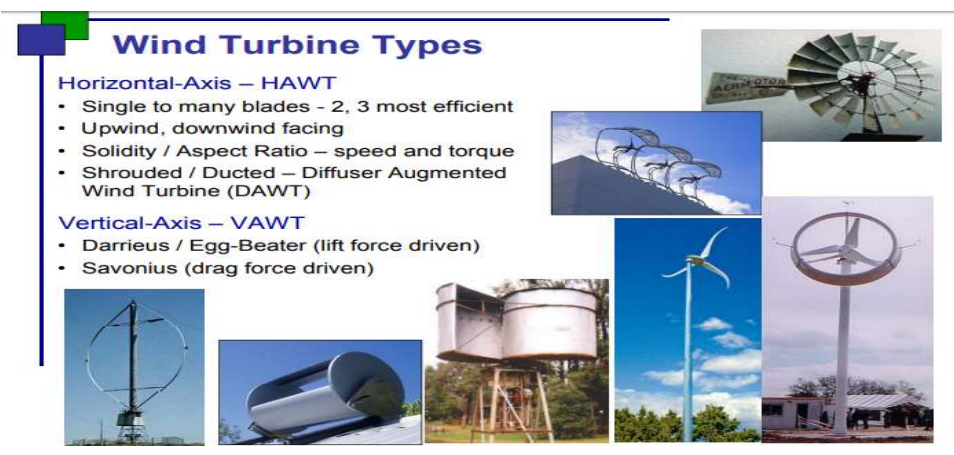

Fig.4. Wind Turbine Types [18]

\section{Power Curve: \\ Capacity Factor}

a) The part of the year the turbine generator is working at evaluated (top) control

Limit Factor $=$ Average Output/Peak Output $\approx 30 \%$

b) CF depends on both the attributes of the turbine and the site qualities (ordinarily 0.3 or above for a decent site)

Figure 5 demonstrates a power bend for a $1500 \mathrm{~kW}$ turbine.

\section{Power Curve of $1500 \mathrm{~kW}$ Turbine}

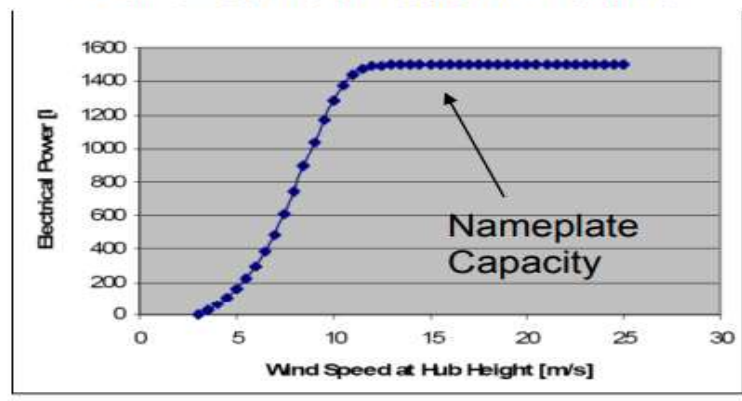

Fig.5. (a) Power curve for a $1500 \mathrm{~kW}$ turbine,
Wind Frequency Distribution

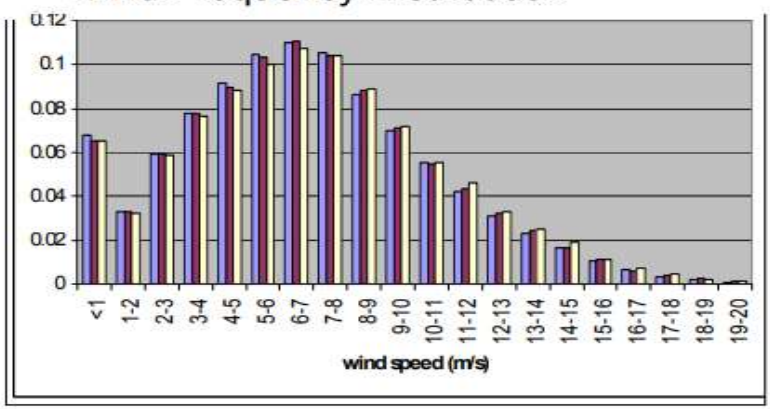

(b) Wind Frequency Distribution

\section{Fundamental Equation of Wind Power:}

Wind Power depends on the amount of air (volume), the speed of air (velocity), the mass of air (density), flowing through the area of interest (flux)-

Kinetic Energy definition: $\mathrm{Ke}=\frac{1}{2} m v^{2}$

Power is KE per unit time. $\mathrm{p}=\frac{1}{2} m v^{2}$

Fluid mechanics gives mass flow rate (density * volume flux):

Thus:

$$
\mathrm{dm} / \mathrm{dt}=\rho * A * v
$$

$$
\mathrm{P}=\frac{1}{2} \rho A v^{3}
$$

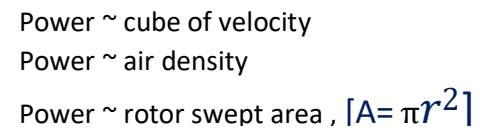

\subsection{Wind speed-}

Wind speed is one in everything about chief basic qualities in elective energy generation. Wind speed changes in each time and house, controlled by a few components equal geographic and climatic conditions. because of wind speed could be a variable parameter; estimated wind speed information regularly takes care of exploitation connected science techniques. Wrongdoing waves commonly outline the diurnal varieties of normal breeze speeds. As partner illustration, diurnal varieties of hourly breeze speed esteem, which are the run of the mill figured qualities that help data in the vicinity of 1970 and 1984, in Dhahran, Asian country demonstrated the curved design. The wind speeds progressed in the daytime and in this way the most velocity happens at concerning threep.m., demonstrating that the daytime wind speed is relating to the nature of light. George et al. reportable that breeze speed at urban concentration, Lone-Star State is close relentless all through dull hours, 
and takes after a twisted illustration all through sunlight hours. A short time later, George et al. have incontestable that diurnal breeze plans at five regions inside the prairie take after an illustration the same as that educated in. Maintained the breeze speed was learning for the total 1970-2003 from up to sixty-six inland areas around the United Kingdom, Sinden has over that month to month average breeze speed is correspondingly propositional to the month to ordinary month temperature, i.e. it's higher inside the winter and minor inside the pre-summer. The most extreme breeze speed happens in the Gregorian date-book month and like this the base in August. Hassan and Hill have reportable that the month-to-month assortment of low breeze speed regards over the measure of 1970-1984 at Dhahran, the Asian nation has exhibited the wavy illustration. Regardless, as a result of the assortment in temperature at Dhahran is negligible over the whole year, there's no a clear connection between's breeze speed and temperatures. The year-to-year assortment of yearly mean breeze speeds depends extraordinarily on picked zones as there's no first association with anticipating it. Perhaps, alongside various years, the yearly mean breeze speeds decrease all the technique from 1970 to 1983 at Dhahran, Saudi Arabia. In the UK, this theatrical presentation in an outstandingly a lot of American state actuated matter for the total 1970-2003.

Mostly, A critical variable in the average yearly breeze speed over a 20 -year time span (1978-1998) is to be noted, and the more significant part of the base qualities begin from under 7.8 to very nearly $9.2 \mathrm{~m} / \mathrm{s}$. The semipermanent learning of the breeze (1978-2007) got from the concise perception framework controlled by the mechanical meteorological observatories was investigated and announced by $\mathrm{KO}$ et al. The outcomes demonstrate that the change of the mean yearly breeze speed occurs at the exact destinations; it tends to diminish somewhat on Jeju Island, while the 2 contradicting locales have irregular trends.[23-28]

\subsection{Wind Direction:}

Wind heading Wind course is one in everything about breeze attributes. Connected science learning of twist headings over an expanded measure of your chance is amazingly vital inside the site decision of intensity plant and subsequently the design of twist turbines inside the power plant. The climate graph chart might be a formidable apparatus of dissecting wind learning that square measure concerning twist headings at a specific location over a chose principal amount (year, season, month, week, and so on.). This round outline shows the recurrence of twist headings in eight or sixteen foremost bearings. As partner degree case appeared in Fig. 6, there square measure sixteen outspread lines inside the climate outline graph, with $22.5^{\circ}$ except for each other. The length of each line is corresponding to the recurrence of wind bearing. The repetition of quiet or near breeze is given as assortment inside the focal circle. Some climate graph outlines may moreover contain the information of wind speeds.[36-42]

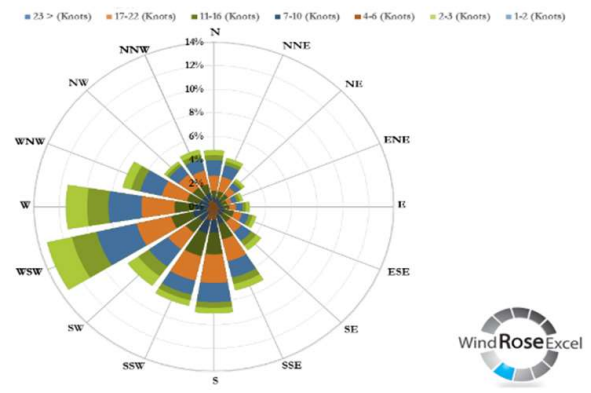

Fig. 5. Windrose diagram for wind directions.

\subsection{Wind turbine controls:}

Wind turbine administration frameworks still assume fundamental parts for ensuring turbine stable and safe task and to upgrade wind vitality catch. The most administration frameworks in an exceedingly popular turbine body pitch administration, slow down administration (uninvolved and dynamic), yaw administration, and others. Beneath wind speed conditions, the capacity yield from a turbine may surpass its appraised worth. Along these lines, control administration is expected to manage the capacity yield among reasonable American state uctuations for maintaining a strategic distance from rotating motor mischief and settling the capacity yield. There are two essential administration routes inside the power administration: pitch administration and slow down control. The turbine control framework is utilised to manage the capacity yield among reasonable variances.

\subsection{Wind turbine configuration:}


A significant portion of the modern monstrous breeze turbines ar flat pivot turbines with for the most part 3 cutting edges. As appeared in Fig. 6, a turbine is included a walled in area, that is situated on the most astounding of a breeze tower, lodging the principal rotating motor components inside. Three cutting edges (not appeared) mounted on the rotor centre point, that is associated using the most shaft to the rigging case. The rotor of the generator is related to the yield shaft of the apparatus case. In this way, the moderate turning pace of the rotor centre point is misrepresented to a coveted high pivoting rate of the generator rotor. Exploitation the pitch framework, each sharp edge is pitched independently to improve the approach of the cutting edge for allowing the following vitality catch in the shared task and for shielding the revolving motor components (edge, tower, and so forth.) from harming in crisis things. With the input info corresponding to estimated moment wind course and speed from the weathervane, the yaw system provides the yaw introduction administration for ensuring the rotational motor unendingly against the wind.[30-35]

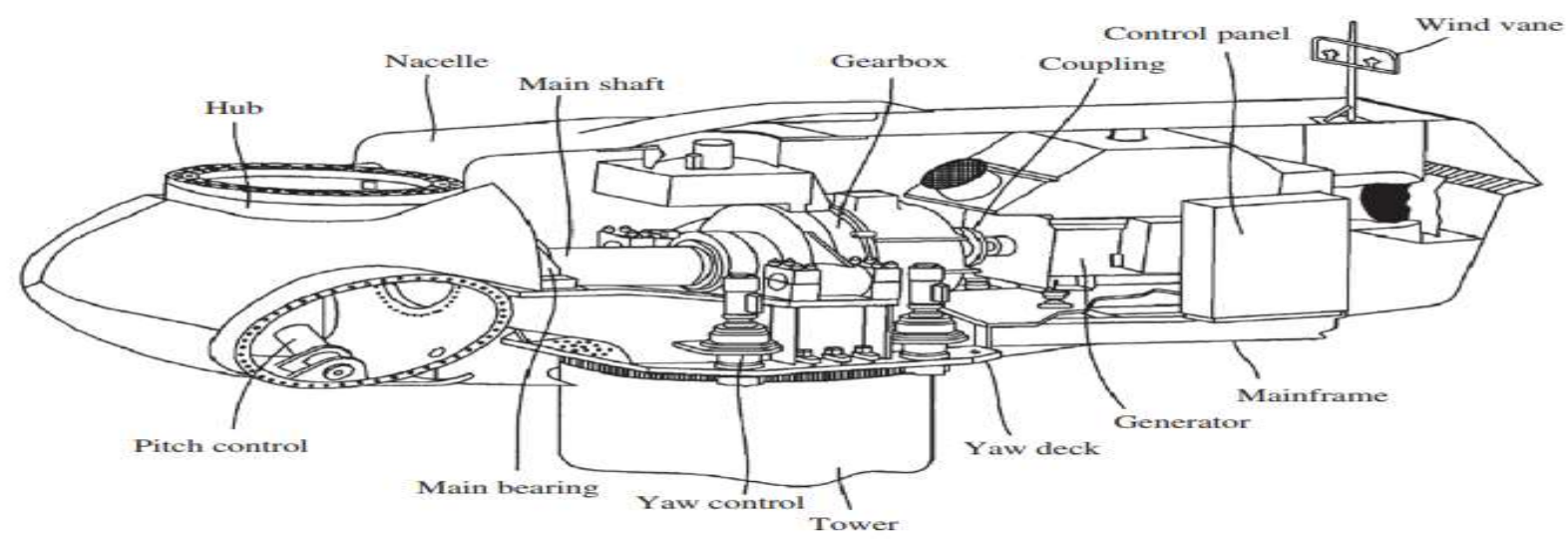

Fig. 6. A horizontal-axis wind turbine configuration (horizontal-axis wind)

\subsection{Wind turbine lifetime:}

Present day wind turbines are intended for an administration lifetime of 20-30 years. Rotating motor manufacturers and elective vitality plants confront the critical test of knowing the best approach to achieve benefit life objectives while limiting support and repair costs. Notwithstanding, up operational trustworthiness and expanding the lifetime of wind turbines are unpleasantly troublesome assignments for some reasons:

a) Wind turbines ought to be presented to changed antagonistic conditions worship extreme temperatures, wind speed variances, moistness, dust, radiation, lightning, saltiness, and successive storms of rain, hail, snow and sand.

b) The contemporary turbine includes a sizable measure of components and frameworks; everything about has his own life. By the Cannikin law, disappointment ought to happen first inside the part or structure with the briefest life.

c) A turbine is liable to a massive kind of great masses given twist vacillations in rapidity \& course and different begins and rests of the structure. Specific real mechanisms should face critical weakness masses.

d) Advanced high malleable and exhaustion safe materials are fundamental for a couple of critical components of substantial fashionable breeze turbines due to the constant increment in cutting edge length, container stature and turning motor weight.

e) As a rich building framework, a \{wind turning engine|turbine\} ought to be outlined at the framework level rather than at the part/part level as a standard application for a couple of turbine makers.[29]

\section{Wind Energy- Challenges:}

\subsection{Technical:}

According to statics, the added substance wind age ranches ability in the Asian nation were found around one,380 MW before 2002. Right now wind age represents eight.7 p.c of the put in control ability in the Asian country anyway it exclusively contributes one. Six p.c of the office generated12. Indian breeze age as of now includes a lower Plant proportion (PLF) contrasted with fuel, atomic and hydropower plants and it's furthermore low if we tend to compare it and universal principles. The centre reason for this issue is because of the more significant part of windage cultivates in the Asian nation are come to up to its charged sum and needs repowering. Repowering won't exclusively encourages them to remain beneficial anyway also may create a shot 
of intensity age capacity change to their best playing locales. According to ponders, repowering of late breeze homesteads may build the breeze vitality PLFproportion significantly from fifteen p.c to thirty p.c. It's been found that inside the nonappearance of right government arrangements structure and appropriations, a few breeze age partnerships don't appear to will to repower their plants that are imperative to beat this impediment. MNRE ought to got to inspire such late breeze ranches for repowering their capacity by supporting with brilliant and $\log$ terms approaches.

\subsection{Infrastructural:}

Vacillations in network recurrence and voltage deliver challenges in powerhouse activities and cut back the potential outcomes for fruitful breeze vitality lattice entrance, that is shown in reports 13. Since of the constraint of a network framework, it's been discovered that the quantity of vitality made from wind ranches couldn't be viably transmitted all through to clients cause wastage of life. MNRE has detected this issue and aggregated in its provide details regarding "Environmentally friendly power Energy Corridors", that distinguishes the foundation interest for departure and transmission of the sustainable power source, together with wind 14 and additionally wanted Germany's participation to convey propelled matrix joining innovation to the Asian nation.

\subsection{Economic:}

High borrowing prices in Asian country creates the obstacle for wind energy sector growth. The project funding methodology applied for a majority of wind generation comes area unit planned with 70: thirty debt equity magnitude relation, that additionally with high-interest rates that create a rich debt under troublesome political economy conditions of the Asian country.

Other Issues in Wind Power Development in India:

a) Forest arrive freedom, e.g. in Karnataka,

b) Creation of a framework for control clearing and transmission offices,

c) Availability of land for wind ranches,

d) Potential arrive generally obtained by producers/engineers,

e) Implementation of updated levy according to CERC rules,

f) Development of planning and anticipating framework (industry and LDCs not yet wholly arranged),

g) Withdrawal of Accelerated Depreciation.

\section{Trends in wind turbine Developments and wind power:}

Wind revolving motor innovation has been produced by continually upgrading turbine style, rising turning motor execution, and improving general rotating motor efficiency. There are numerous ages of advancement and change in turbine innovation, focusing on cutting edges, generators, coordinate drive methods, pitch and yaw administration frameworks, et cetera. to deliver extra power from twist innovation inside the following numerous decades, it needs:

a) Developing inventive procedures

b) Decreasing wind turbine costs through innovation progression

c) Optimizing fabricating forms and upgrading producing activities

d) Improving wind turbine execution and efficiency

e) Reducing working and support costs

f) Expanding wind turbine generation limits. The present significant patterns in the advancement of wind turbines are towards a higher power, higher productivity and consistent quality, and lower cost per kilowatt machines.

\section{Conclusion:}

A sustainable solution is evident that the utilisation of wind energy as a permanent resolution to this world energy considerations may well be property. Even so, conditions for the property are evaluated. As a result, albeit the resource in its current state of technology is useful enough to be able to support numerous developments within the business, achievements of vast technological opportunities might find yourself creating the resource unlimited. At the financial level, wind energy has proved to be not solely environmentally however additionally socially profitable to financially reinforce wind business whereasceasing to price competition. Many governments square measure of the read that the wind businesses ready to require up to the opened business, with a new certificate market taking over all the favour. Even so, about the little market, there ought to be the maintenance of a set value system. Socially, the reality that the wind business is taking part in native development 
encourages for its property. Besides, its checked authentic influence on the native inhabitants might facilitate in crippling the general public temperament. Finally, it's necessary to push for more analysis regarding potential environmental analysis. It is, therefore, judicious to 1st rethink results of studies associated ecological impact analysis once thinking of golf shot up a replacement power plant or reconsidering a previous one.

\section{Acknowledgements}

The authors would like to dedicate this paper to His Parents for his valuable guidance and continuous encouragement to successfully completion of this work.

\section{Reference}

[1] Wang, X.C., Guo, P. also, Huang, X.B. (2011) A Review of Wind Power Forecasting Models. Vitality Procedia, 12, 770778. http://dx.doi.org/10.1016/j.egypro.2011.10.103

[2] Zhao, D.M., Zhu, Y.C. also, Zhang, X. (2011) Research on Wind Power Forecasting in Wind Farms. Procedures of the 2011 IEEE Power Engineering and Automation Conference, Wuhan, 8-9 September 2011, 175-178. http://dx.doi.org/10.1109/PEAM.2011.6134829

[3] Sideratos, G. also, Hatziargyriou, N.D. (2007) An Advanced Statistical Method for Wind Power Forecasting. IEEE Transactions on Power Systems, 22, 258-265. http://dx.doi.org/10.1109/TPWRS.2006.889078

[4] Ma, L., Luan, S.Y., Jiang, C.W., Liu, H L. also, Zhang, Y. (2009) A Review on the Forecasting of Wind Speed and Generated Power. Inexhaustible and Sustainable Energy Reviews, 13, 915-920. http://dx.doi.org/10.1016/j.rser.2008.02.002

[5] Lange, M. what's more, Focken, U. (2008) New Developments in Wind Energy Forecasting. Procedures of the 2008 IEEE Power and Energy Society General Meeting, Pittsburgh, 20-24 July 2008, 1-8.

[6] Zhao, X., Wang, S.X. What's more, Li, T. (2011) Review of Evaluation Criteria and Main Methods of Wind Power Forecasting? Vitality Procedia, 12, 761-769. http://dx.doi.org/10.1016/j.egypro.2011.10.102

[7] Chong Han, Alex Q. Huang, Wayne Litzenberger, Loren Anderson, Abdel-Aty Edris "STATCOM Impact Study on the Integration of a Large Wind Farm into a Weak Loop Power System", (1266-1272), 2006.

[8] Katsuhisa Yoshimoto, Toshiya. Nanahara, Gentaro Koshimizu, Yoshihsa Uchida "New Control Method for Regulating State-of-Charge of a Battery in Hybrid Wind Power/Battery Energy Storage System", (1244-1251), 2006.

[9] http://www.wwindea.org

[10] EWEA yearly report, "Winning with European Wind Creating power, helping the earth", 2008.

[11] B.C. Ummels, E. Pelgrum, W.L. Kling "Joining of huge scale wind power and utilisation of vitality stockpiling in the Netherlands' power supply", 2007.

[12] Dany G. "Power save in interconnected frameworks with high breeze control generation", 2001.

[13] H. Holttinen et al. "Outline and Operation of Power Systems with Large Amounts of Wind Power, first aftereffects of IEA joint effort", 2007.

[14] Mary Black, Goran Strbac "Estimation of capacity in giving adjusting administrations to power age frameworks with high wind penetration", 2005.

[15] WWEA, "World breeze vitality report 2008", South Korea, 2009.

[16] http://www.pikeresearch.com/inquire about/vitality stockpiling technology markets

[17] Magnus Korpås "Appropriated Energy Systems with Wind Power and EnergyStorage",2004

[18] Wind Power Wind Power Fundamentals Presented by Alex Kalmikov and Katherine Dykes With commitments from Araujo PhD Candidates, MIT Mechanical Engineering,

[19] MNRE got to at http://bit.ly/14woYJX (2013)

[20] http://bit.ly/15WqKDm (2013)

[21] India wind vitality standpoint 2012, got to at http://www.gwec.net/wp-content/transfers/2012/11/IndiaWind-EnergyOutlook-2012.pdf

[22] A Review of Wind Energy Scenario in India, International Research Journal of Environment Sciences, ISSN 2319- 1414 Vol. 3(4), 87-92, April (2014) Int. Res. J. Condition Sci.

[23] [Siddiqi, A.H., Khan, S. and Rehman, S., Wind speed reenactment utilising wavelets. American Journal of Applied Sciences, 2(2), pp. 557- 564, 2005.

[24] George, J.M., Peterson, R.E., Lee, J.A. and Wilson, G.R., Modeling wind and relative dampness impacts on air quality. Int. Claim to fame Conf. on Aerosols and Atmospheric Optics: Radiative Balance and Visual Air Quality, Snowbird, Utah, 


\section{Gyancity Journal of Engineering and Technology, Vol.4, No.2, pp.29-37, July 2018 \\ ISSN:2456-0065 DOI: 10.21058/gjet.2018.42004}

[25] George, J.M., Wilson, G.R. and Vining, R.C., Modeling hourly and day by day wind and relative dampness. Int. Conf. on Air Pollution from Agricultural Operations, pp. 183- 190, Ames, Iowa, 1996.

[26] Sinden, G., Characteristics of the UK wind asset: long-haul examples and relationship to power request. Vitality Policy, 35(1), pp. 112- 127, 2007.

[27] European Wind Energy Association. Wind vitality - the certainties, part I: Technology, The yearly fluctuation of wind speed 2009

[28] [Hassanm, Y.H. and Hill, D.R., Islamic Technology: An Illustrated History, Cambridge University Press, 1986.

[29] Fundamentals of wind vitality Wei Tong Kollmorgen Corporation, Virginia, USA. Mind Transactions on State of the Art in Science and Engineering, Vol 44, (C) 2010 WIT Press

[30] [Adam, D., Floating breeze turbines ready to outfit sea winds, http://www.guardian.co.uk/condition/2008/jul/16/windpower. renewable energy

[31] Sway, Principles of the idea, http://sway.no/index.php?id=16

[32] [Vanderover, J.S. and Visser, K.D., Analysis of a contra-pivoting propeller driven transport airship, ftp://ftp.clarkon.edu/.depts/mae/public_html/papers/vanderover.pdf

[33] Schönball, W., Electrical generator course of action, US Patent 3,974,396, 1976.

[34] McCombs, J.C., Machine for changing over breeze vitality to electrical vitality, US Patent 5,506,453, 1996.

[35] Wachinski, A., Drive gadget for a windmill gave two counter-rotative propellers, US Patent 7,384,239, 2008.

[36] Shin, C. and Hur, M.C., Over-drive equip gadget, US Patent 5,222,924, 1993.

[37] Shin, C., Multi-unit rotor cutting-edge framework coordinated breeze turbine, US Patent 5,876,181, 1999.

[38] Kowintec Corp., http://www.kowintec.com/english/items/main.html

[39] Korane, K.J., Flexible apparatuses support wind-turbine dependability. Machine Design, 79(15), pp. 24-28, 2007.

[40] Fox, G., Epicyclic apparatus framework, US Patent 7,056,259, 2006.

[41] Musial, W., Butterfi eld, S. and McNiff, B., Improve wind turbine gearbox dependability. 2007 European Wind Energy Conf., Milan, Italy, 2007.

[42] Gbur` sick, P., Gbur sick, V., Gavrilov, M., Srdanovi` c, V. and Mastilovic', S., Complementary administrations of sun oriented and twist vitality in Serbia. Geographica Pannonica, 10, pp. 22-25, 2006. 